\title{
Analytical evaluation of current starch methods used in the international
}

\section{sugar industry: Part I}

\author{
Marsha Cole, ${ }^{1 *}$ Gillian Eggleston, ${ }^{1}$ and Alexa Triplett ${ }^{1}$ \\ ${ }^{*}, 1$ USDA-ARS Southern Regional Research Center \\ 1100 Robert E. Lee Boulevard \\ New Orleans, LA, 70124, USA \\ Tel: +1 (504) 2864437 \\ Fax: +1 (504) 2864367 \\ marsha.cole@ars.usda.gov
}

\begin{abstract}
Several analytical starch methods exist in the international sugar industry to mitigate starchrelated processing challenges and assess the quality of traded end-products. These methods use iodometric chemistry, mostly potato starch standards, and utilize similar solubilization strategies, but had not been comprehensively compared. In this study, industrial starch methods were compared to the USDA Starch Research method using simulated raw sugars. Type of starch standard, solubilization approach, iodometric reagents, and wavelength detection affected total starch determination in simulated raw sugars. Simulated sugars containing potato starch were more accurately detected by the industrial methods, whereas those containing corn starch, a better model for sugarcane starch, were only accurately measured by the USDA Starch Research method. Use of a potato starch standard curve over-estimated starch concentrations. Among the variables studied, starch standard, solubilization approach, and wavelength detection affected the
\end{abstract}


sensitivity, accuracy/precision, and limited the detection/quantification of the current industry starch methods the most.

Keywords: sugarcane; simulated raw sugar; total starch method; method comparison

\section{Introduction}

Starch is a natural sugarcane impurity that greatly influences raw sugar quality and affects factory and refinery processing. Starch occurs in the sugarcane crop as insoluble granules that consist of amylose (linear) and amylopectin (branched) glucopolysaccharides, and these granules are extracted into factory juices by tandem-milling or diffusion (Chen \& Chou, 1993). In recent years, there has been a world-wide increase in starch concentrations mostly because of one or a combination of the following: (i) increased mechanical processing of green sugarcane; (ii) varying environmental conditions; and (iii) newer sugarcane varieties with higher starch content (Eggleston et al., 2013a). Regardless of the starch concentration or physical form entering into the factory, until 2013 it was previously presumed that all of the granular starch (insoluble starch) in the extracted juices became solubilized after undergoing clarification and evaporation in the factory (Godshall et al., 1991). This was because the clarification and evaporation stages have the longest retention time and are heat-intensive, thus facilitating starch swelling and solubilization (Eggleston et al., 2016a). However, it has since been unequivocally proven that solubilizing insoluble starch from grass crops, i.e., sugarcane and corn starch, is difficult (Cole et al., 2013). Several factors that govern starch solubilization during sugarcane factory processing include heating time and temperature, Brix, and starch concentration (Cole et al., 2013). Therefore, any insoluble starch that has not become completely solubilized during the factory 
clarification process will persist into syrups, massecuites, molasses, raw sugars and even refined sugars (Eggleston et al., 2013b; Cole et al., 2014), and sometimes in considerable amounts. This occurrence is worse when high starch sugarcane is delivered to a sugarcane factory, such as during the 2011 and 2012 processing seasons in Louisiana, USA (Eggleston et al., 2013b).

The new knowledge that more insoluble starch is present across the sugarcane factory and refinery than previously considered has multiple, serious processing implications. Unfortunately, current factory methods do not measure insoluble starch (Eggleston, 2014), but a new USDA Starch Research method is able to measure insoluble, soluble, and total starch in multiple cane products (Cole et al., 2016c). This USDA starch method has provided large amounts of new information about how insoluble starch affects processing at sugarcane factories and refineries. In the sugarcane factory, insoluble starch can increase syrup viscosity and reduce sugar recovery (Eggleston et al., 2016b; 2016c). $\alpha$-Amylases can help to mitigate starch-related viscosity challenges at the factory ( $\alpha$-amylase is not typically added at the refinery because the high Brix liquors are not optimum for amylase action). Cole et al. (2013) reported that $\alpha$-amylases preferentially hydrolyze different starch forms in this order: soluble starch $>$ swollen starch>insoluble starch. At the refinery, it was revealed that insoluble starch (i) was more detrimental to raw and white sugar filterability than soluble starch, (ii) reduced carbonatation reaction rates, (iii) promoted the formation of unwanted calcium carbonate crystal fines $(<5 \mu \mathrm{m})$, (iv) critically affected filtration flow rates when in the presence of soluble starch, (v) required greater amounts of milk of lime to facilitate carbonatation reactions, and (vi) helped to form unwanted channels in the decolorization beds (Cole et al., 2016a; 2016b; Jack Thompson, LSR refinery, personal communication). 
Several international organizations, e.g. International Commission for Uniform Methods of Sugar Analysis (ICUMSA), Bureau of Sugar Experiment Stations (BSES), and the South African Sugar Association (SASTA), as well as sugar institutions, currently have analytical methods available which are used to measure total starch in various factory and refinery products, particularly including raw sugars. Many of these industrial methods are similar, using iodometric chemistry to measure the total amount of starch, but differ in starch solubilization, type of starch reference, detection wavelength, and applicable cane product (Table 1). Collaborative starch tests have been recommended (Thielecke, 2002; 2004), yet, only a limited comparison of the methods have been undertaken (Eggleston, 2014; Harrison, 2012; Matic, 1971). With the development of the USDA Starch Research method that is based on microwave-assisted probe-ultrasonication and can measure total, insoluble, and soluble starch, uses a corn starch reference, and includes a colour blank, current industrial methods can now be comprehensively evaluated.

In light of (i) the new developments in sugarcane insoluble starch and (ii) because there are no official industrial starch methods for multiple cane products, including juices, syrups, massecuites and molasses, an investigation to evaluate the current industrial starch methods in comparison to the USDA Starch Research method was undertaken. This, Part I of the investigation compares the analytical merit, accuracy, and precision of the current industrial starch methods using simulated raw sugars either containing potato (easy to solubilize) or corn starch (difficult to solubilize and physico-chemically similar to sugarcane starch). The effects of each variable, i.e., starch standard, wavelength selection, concentration and components of iodometric reagents, and solubilization method, was also discussed. In Part II (Cole et al., 2017), the starch methods are compared using factory raw sugars with emphasis on colour correction 
and ability to convert results from one method to another, an inquiry from the international sugar industry.

\section{Materials and methods}

\subsection{Chemicals and sugar samples}

Corn starch, potato starch, sucrose $(99.95 \%)$, and other chemicals were analytical grade and purchased from Sigma Aldrich Company (St. Louis, MO, USA).

\subsection{Simulated raw sugars}

Simulated raw sugars were prepared by adding dry potato or corn starch ( 0.33 to $3.00 \mathrm{~g})$ to a sealable container of $3 \mathrm{~kg}$ analytical grade sucrose and shaken to evenly disperse the starch throughout the sugar sample and create a stock sugar sample. The final concentration of starch in the simulated raw sugars was 110,500 , and $1000 \mathrm{mg} / \mathrm{kg}$ sucrose. From this source, aliquots of sugar solution were made and then analyzed with current starch industrial and research methods.

\subsection{Industrial starch methods}

Total starch content of six simulated raw sugars were analysed with the following methods, used worldwide: Colonial Sugar Refinery (CSR) Method (Davis, 1970), Charles Method (Charles, 1968), ICUMSA GS 1-16 (ICUMSA, 2013), ICUMSA GS 1-17 (ICUMSA, 2013), SMRI (Schoonees-Muir et al., 2009), and SASTA Method 7.9 (Schoonees-Muir et al., 2009). A summary of these methods are listed in Table 1 . The industrial methods were also compared to the USDA Starch Research method (Cole et al., 2016c). The USDA Starch Research method 
uses microwave-assisted probe ultrasonication to efficiently swell (gelatinize) and rupture (solubilize) starch granules for quantificiation (Cole et al., 2016c). To date, the USDA Starch Research method is the only method that can solubilize corn starch and measure total, insoluble, and soluble starch concentration in multiple cane processing products and by-products (Cole et al., 2016c). All methods were performed twice with triplicate measurements $(\mathrm{N}=6)$.

\subsection{USDA Starch Research method}

The USDA Starch Research method of Cole et al. (2016c) was used without modification. Briefly, $15 \mathrm{~g}$ of sugar was dissolved in $85 \mathrm{ml}$ deionized water (15 Brix). A $10 \mathrm{ml}$ sample aliquot was weighed in $125 \mathrm{ml}$ Erlenmeyer flask covered with a watch glass and then microwaved for 60 $\mathrm{s}$ at the $100 \%$ power setting, i.e., $1100 \mathrm{~W}$ emitting $\sim 12 \mathrm{~W} / \mathrm{cm}^{2}$ (Kenmore $1100 \mathrm{~W}$ household microwave oven) to the sample; this produced swollen starch. The sample was cooled on ice for $1 \mathrm{~min}$, reweighed, and readjusted with deionized water to account for any water loss caused by microwaving. The $10 \mathrm{ml}$ solution was transferred to a $75 \mathrm{ml}$ test tube and subjected to $5 \mathrm{~min}$ of probe sonication at $15.8 \mathrm{~W} / \mathrm{cm}^{2}(60 \%$ amplitude setting on the VCX750 sonicator, Sonics \& Materials, Newton, CT, USA). Although small, any water losses from sonication were also added back by weight. The sugar solution was then filtered into disposable cuvettes. Aliquots $(0.8 \mathrm{ml})$ of the probe-treated starch solutions were stained with $0.2 \mathrm{ml}$ of $0.25 \mathrm{M} \mathrm{HCl}$ and $1 \mathrm{ml}$ of iodometric reagents $(1 \mathrm{mM} \mathrm{KIO} / 5 \mathrm{mM} \mathrm{KI}$ solution) before measuring at $600 \mathrm{~nm}$ on a spectrophotometer (UVmini-1240, Shimadzu, MD, USA). In this study, the colour blank was omitted since all solutions were colourless. An iodometric blank was prepared in a cuvette containing: $0.8 \mathrm{ml}$ deionized water, $0.2 \mathrm{ml}$ of $0.25 \mathrm{M} \mathrm{HCl}$, and $1 \mathrm{ml}$ iodometric reagents. Starch 
concentrations were determined from a corn starch standard curve, unless otherwise noted. Results are an average of two experiments with triplicate measurements $(\mathrm{N}=6)$.

\subsection{Absorbance spectroscopy}

The iodometric reagents from each method were prepared without modification in either the presence or absence of 200 ppm corn starch solubilized by the USDA Starch Research Method. All reagents were proportionately added to either a $0.8 \mathrm{ml}$ starch sample or water. Absorbance spectroscopy was measured using an Evolution 60S UV-Visible spectrophotometer (Thermoscientific, Waltham, MA, USA) from 250 to $800 \mathrm{~nm}$ in a Suprasil quartz cuvette (45 x12.5 x $12.5 \mathrm{~mm}, 10 \mathrm{~mm}$ path length, $700 \mu \mathrm{l}$ volume) from Sigma Aldrich Company (St. Louis, MO, USA) against a water background. Spectra were processed using Visionlite Scan software version 5.2, also from Thermoscientific.

\subsection{Statistical analysis}

All starch data was analysed using a paired-samples-t-test and ANOVA to compare the accuracies of each method (JMP SAS v. 11.2, Cary, NC, USA). Means were separated using Tukey's HSD test $(\mathrm{p}<0.05)$. Data for each analytical parameter was analyzed separately for each raw sugar. Pearson correlation (R) coefficients were used to assess the relationship and significance between industrial starch methods. Predicted equations were also determined with JMP v. 11.2 by fitting lines to equated standard curves and sugar results. Percent accuracy (\%) was calculated as follows: [1 - (|Factory Method Starch Result - USDA Starch Research Method Starch Result|/ USDA Starch Research Method Starch Result)] x 100\%.

\section{Results and discussion}




\subsection{Evaluation of starch method protocols}

Starch methods currently used in the world-wide sugar industry are iodine-based, and measure "total" starch, but actually mostly measure soluble starch in the sugar product (Cole et al., 2014). Basically in these methods, starch in sugar products are "solubilized" and then the soluble starch concentrations are treated with iodine to form a starch-iodine complex (blue colour) that is measured with either a spectrophotometer or colorimeter and quantified against a potato or amylopectin starch reference (Table 1). Many of these methods have the advantage of being easy to perform but vary in the applicability to a high-throughput sampling environment and use of glassware. The Charles method is the easiest and quickest to perform since it only requires the dissolution of sugar and the addition of iodometric reagents; however, constructing the standard curve required more steps. Likewise, ICUMSA GS1-16 and GS1-17 methods are rapid, use common laboratory glassware, and do not require transferring the samples until the final absorbance measurement step. Although not commonly used, the CSR method requires extensive glassware and sample handling, and special care has to be taken to continuously stir the sample during the boiling stages, which poses a safety risk. The SASTA method also requires extensive glassware but is not excessively laborious. In strong contrast, the SMRI method is the most laborious and complicated, requiring long sample processing times in addition to a $1 \mathrm{~h}$ precipitation step and need for adequate vacuum filtration. It also uses large quantities of organic solvent, which would be better served in a research lab rather than factory setting with limited ventilation. On the other hand, all the methods use equipment and supplies usually available in factory and refinery laboratories. The USDA Starch Research method, although fast, reproducible, and applicable to all factory products and by-products (Cole et al., 2016c), uses an inexpensive household microwave (\$100 USD) and an industrialprobe ultrasonicator $(\$ 7,000$ 
USD); the cost of the probe ultrasonicator may be cost-prohibitive ( $\$ 7,000$ USD) to some factories and refineries and limit its widespread use. This method, however, is not difficult or laborious and should be amenable to the needs of a high-throughput factory setting.

\subsection{Effects of potato and corn starch reference materials to create standard curves}

Current sugar industry starch methods measure sugarcane starch calibrated to potato starch (Table 1), because (i) potato starch is easy to solubilize in boiling water and (ii) sugarcane starch is not commercially available for use as a standard. After comparing standard curves from potato, rice, and corn starches that were boiled in water (conductive heating), Godshall et al. (2004) advocated the need to use potato starch as a reference for starch methods because it was completely solubilized in $5 \mathrm{~min}$, whereas the corn and rice starches were not. This explains why potato starch has been a common starch reference used across the sugar industry. This is despite its different polysaccharide composition (amylose to amylopectin ratios) and physical properties to sugarcane starch. Corn starch, however, is considerably more similar to sugarcane starch than potato starch (Eggleston et al., 2013b; Figueira et al., 2011), even having comparable amylose to amylopectin ratios (BeMiller \& Whistler, 2009; Blake et al., 1985). This is not surprising as both sugarcane and corn belong to the grass (Poaceae) family. Furthermore, it has been unequivocally shown that, during industrial sugarcane processing, sugarcane starch behaves similarly to corn starch in that it is also difficult to solubilize (Cole et al., 2013; 2014). Since the new USDA Starch Research method can completely solubilize corn starch, it was used to assess the differences among industrial starch methods using corn or potato starch in simulated sugars.

Fig. 1 shows the calibration (standard) curves for the six international starch methods, which used either potato starch or amylopectin as a reference. Also included in Fig. 1, is the calibration curve for the USDA Starch Research method, which uses corn starch standard, for comparison. 
For each method, strong, linear correlations $(\mathrm{R}=0.99)$ existed with variable sensitivities or slope values (Fig. 1). The sensitivities (slope) of each method decreased ( $<<0.05)$, regardless of the type of starch standard used: ICUMSA GS1-17 $\geq$ SMRI $>$ USDA Starch Research Method $>$ Charles $>$ SASTA $>$ CSR $\geq$ ICUMSA GS1-16 (Fig. 1A). Each method also covered different starch concentration ranges (Table 1 and Fig. 1A). The limits of detection (LOD) and quantification (LOQ) are also listed in Table 1. The USDA Starch Research method had the lowest LOD and LOQ, indicating that the research method is the only method available that is applicable to very-low starch containing raw sugars and refined sugars (Table 1). The LOD and LOQ values for the industrial methods indicated that these methods have limited applicability to raw and refined sugars, however, all of these methods are capable of quantifying starch that is near or exceeds the 150 and $250 \mathrm{mg} / \mathrm{kg}$ starch limits as penalty threshold values set by South Africa and the U.S.A. sugar refineries, respectively (Table 1).

The type of starch reference, i.e., corn or potato starch, used in the international starch methods affected their sensitivities; this effect was illustrated using the USDA Starch Research method (Fig. 1B). Note: Because the USDA method is known to completely solubilize corn and potato starches, it was used to evaluate the effects of the starch standard without the interference of other variables, and to address the concern of using a potato starch as a standard despite the similarity of sugarcane starch to corn starch. As expected, an increase in starch concentration resulted in an increase in starch-triiodide absorbance (Fig. 1B). As concentrations continuously increased, however, there was a $>15 \%$ divergence between the standard curves, demonstrating preferential sensitivity to the corn starch curve (Fig. 1B). When potato starch was used as a standard, curves were $\sim 22 \%$ less sensitive than corn starch which yielded a $14 \%$ over-estimation in starch concentrations for equal concentration (Fig. 1B). This is attributable to the different 
ratios of amylose to amylopectin in corn and potato starch that are known to affect iodine binding and the respective absorbance maxima (Baldwin et al., 1944; Figueira et al., 2011). This result indicates that the type of starch reference used can affect method sensitivity and, consequently, quantification. Similar comparisons using the other methods could not be undertaken as they were unable to completely solubilize corn starch.

\subsection{Effect of the wavelength selection}

Wavelength selection can affect solution absorbance and corresponding starch quantification. To explain the role wavelength selection has on the starch method and sensitivity, the concept of colour theory must be briefly explained. Colour theory is a fundamental concept that associates wavelength detection and the visually observed colour of a sample using the frequency of light either emitted or absorbed by the sample (Skoog et al., 1997). Detection wavelengths used in the current starch methods range from $560 \mathrm{~nm}$ to $700 \mathrm{~nm}$ (Table 1), which corresponds to solution colours extending in shades of purple to green, respectively (Fig. 2A). The amount of soluble amylose and amylopectin in solution (attributable to botanical source), which is available to bind with triiodide $\left(\mathrm{I}_{3}{ }^{-}\right)$, affects the visual colour of the solution and optimal detection wavelength. Fig. 2A shows that the intense blue colour from an amylose- $\mathrm{I}_{3}{ }^{-}$complex will be more sensitively detected at its complementary detection wavelength, i.e., $600 \mathrm{~nm}$ (amber yellow), whereas, a solution containing excess amylopectin (red-violet solution colour) will absorb between 545 to $560 \mathrm{~nm}$ (Jarvis \& Walker, 1993). Fig. 2B shows the absorbance profile of 200 ppm solubilized corn starch that was treated with the iodometric reagents from each method. Peak maxima in the absorbance profiles of starch-iodine solutions will range between 580-630 nm depending on the exact polysaccharide ratio, chain length, or degree of branching (Jarvis \& Walker, 1993; 
Murdoch, 1992; Yu et al., 1996). Since the amylose content in sugarcane starch ranges between 15-25\% (Alves et al., 2014) and, like corn starch, has slightly more amylose than potato starch (Chen \& Chou, 1993; Cole et al., 2013; Figueira et al., 2011; Godshall et al., 2004), and both sugarcane and corn starches have the same absorbance profile, i.e., $\lambda \max$ of $600 \mathrm{~nm}$ (Figueira et al., 2011), the most suitable industrial starch method should also quantify solubilized sugarcane starch in raw sugars at $600 \mathrm{~nm}$.

Only three of the industrial starch methods, i.e., ICUMSA GS1-17, SASTA, and SMRI, plus the USDA Starch Research method used $600 \mathrm{~nm}$ to measure solubilized starch solutions (Table 1) although all of the methods, except the Charles method, exhibited peaks at $600 \mathrm{~nm}$ (Fig. 2B, peak a). Murdoch (1992) published a similar absorbance profile to Fig. 2B confirming that the $\lambda \max$ at $\sim 600 \mathrm{~nm}$ was attributed to amylose- $\mathrm{I}_{3}{ }^{-}$complexation and responsible for the blue solution colour. The Charles method, however, had a peak maximum at $\sim 480 \mathrm{~nm}$, attributable to the iodometric reagents, with a broad shoulder at $\sim 560 \mathrm{~nm}$ (Fig. 2B, peak b). Considering that the peak shoulder in Fig. 2A overlapped with the amylopectin $\lambda \max$ of $548 \mathrm{~nm}$ (Jarvis \& Walker, 1993), also explains the use of potato amylopectin as a starch standard and corroborated the 560 $\mathrm{nm}$ wavelength selected for the Charles method (Table 1). Amylopectin, however, does not complex well with $\mathrm{I}_{3}{ }^{-}$and therefore, does not have a high absorbance intensity (BeMiller \& Whistler, 2009). Raw sugar colorants invariably give yellow, brown, or reddish colorations with iodine that also overlap the starch $-\mathrm{I}_{3}{ }^{-}$absorption peak in this range (Davis, 1970), thus the 560 nm wavelength may not sensitively quantify the starch- $\mathrm{I}_{3}{ }^{-}$absorbance in raw sugars without incorporating a colour blank (Cole et al., 2017). Overall, the $560 \mathrm{~nm}$ wavelength is not a suitable detection wavelength for starch quantification because the peak at $\sim 560 \mathrm{~nm}$ was not fully resolved, could shift with starch branching, ratio, or chain length, and overlapped with some 
contributors to raw sugar colour, adversely affecting the sensitivity, LOD, and LOQ of the Charles method (Table 1). The Charles method, however, may be better suited for very low colour raw sugars, or even refined sugars, since those impurities would be minimized and not interfere with quantification.

Inspection of the starch- $\mathrm{I}_{3}^{-}$absorbance spectrum for the CSR method revealed a small shoulder at $\sim 700 \mathrm{~nm}$ (Fig. 2B, peak b) that was less resolved than the peak at $600 \mathrm{~nm}$ (peak a). Moreover, increased starch concentrations only affected the $600 \mathrm{~nm}$ peak and did not increase the peak at $700 \mathrm{~nm}$ (data not shown), which explained the limited sensitivity exhibited by the CSR and ICUMSA GS1-16 methods (Fig. 1). This is because starch quantification at $700 \mathrm{~nm}$ is better suited for measuring raw sugar colorants (amber, yellow, green) and polyphenolic colorants (yellow) rather than any $\operatorname{starch}^{-\mathrm{I}_{3}}{ }^{-}$(blue or red-violet) complexes (Zhao et al., 2012). Davis (1970) indicated that a $700 \mathrm{~nm}$ wavelength would bypass any absorbance contribution from common raw sugar colorants, which may have been the motivation for the CSR and ICUMSA GS1-16 methods to use $700 \mathrm{~nm}$ for starch quantification. Cole et al., (2017), however, reported that the absorbance contribution from the natural cane colorants and processing byproducts were still evident at $700 \mathrm{~nm}$ and that this absorbance contribution needed to be corrected by including a colour blank (this will be discussed in Part II of this study). This is especially important since some raw sugar colorants are intense and dominate the starch- $\mathrm{I}_{3}{ }^{-}$ absorbance causing some methods to unintentionally measure sample colour (Cole et al., 2014). In this case, method sensitivity, LOD, and LOQ would be adversely affected (Cole et al., 2017).

Therefore, it is not only critical to select a starch standard, like corn starch, that has comparable polysaccharide ratios as sugarcane starch, but to also understand the differences among the iodometric reagents from each industrial starch method since both directly affects 
amylose- $\mathrm{I}_{3}^{-}$complexation. Several published reports showed that the concentration and composition of iodometric reagents were critical to starch- $\mathrm{I}_{3}{ }^{-}$complexation and directly affected the absorbance profile (Murdoch, 1992; Yu et al., 1996; Yajima et al., 1987). Therefore, the effect of the iodometric reagents on method accuracy and sensitivity for starch quantification is discussed in the next section.

\subsection{Effect of the iodometric reagents}

$$
\begin{array}{lr}
\mathrm{KIO}_{3}+5 \mathrm{KI}+6 \mathrm{H}^{+} \rightarrow 6 \mathrm{~K}^{+}+3 \mathrm{H}_{2} \mathrm{O}+3 \mathrm{I}_{2} & \text { Scheme 1 } \\
3 \mathrm{I}_{2}+{I^{-}}_{\text {Excess }} \leftrightarrow \mathrm{I}_{3}^{-} & \text {Scheme 2 } \\
\text { Starch }+\mathrm{I}_{3}^{-} \leftrightarrow \text { Starch-I }{ }_{3}^{-} \text {(blue) } & \text { Scheme 3 }
\end{array}
$$

The formation, stability, and detection sensitivity of starch-triiodide complexes depends on the concentration of reagents, $\mathrm{pH}$ (acid concentration), and temperature (Moulik \& Gupta, 1984; Woodard, 1934), following the oxidation-reduction reaction in Scheme 1. The exact stoichiometrical molar ratio of 1:5 between $\mathrm{KIO}_{3}$ and $\mathrm{KI}$ is required to form 3 moles of iodine $\left(\mathrm{I}_{2}\right)$ and the subsequent $\mathrm{I}_{3}{ }^{-}$that is needed to complex with starch (Schemes 2 and 3). Iodide ions $\left(\mathrm{I}^{-}\right)$are critical for the rapid formation of $\mathrm{I}_{3}{ }^{-}$and the stability of the starch- $\mathrm{I}_{3}{ }^{-}$complex (Murdoch, 1992). The iodate $\left(\mathrm{IO}_{3}{ }^{-}\right)$species is essential to the oxidation-reduction reaction (Scheme 1), because it forms $\mathrm{I}_{2}$ and then combines with free $\mathrm{I}^{-}$ions to produce $\mathrm{I}_{3}^{-}$(Scheme 2). In this study, the iodometric reagents for the current industrial starch methods had stoichiometrical molar ratios ranging from 1:7 to 1:361 (Table 1). The absorption spectra for the iodometric reagents alone are shown in Fig. 2C. Each industrial starch method used iodometric reagents that were in 
excess, which caused their absorbance profiles to be saturated (Fig. 2C). This was particularly evident in the spectra ranging from 200 to $300 \mathrm{~nm}$, the region attributed to $\mathrm{I}^{-}, \mathrm{I}_{2}$, and $\mathrm{I}_{3}{ }^{-}$(Fig. 2C). Unreacted $\mathrm{I}^{-}$absorbs strongly between 200 and $250 \mathrm{~nm}$ (Mazumdar et al., 2010) and the $\mathrm{I}_{3}{ }^{-}$ monomer gives two characteristic peaks at $288 \mathrm{~nm}$ and $349 \mathrm{~nm}$ (Yu et al., 1996; Murdoch, 1992). Only the industrial starch methods had absorbance peaks attributable to $\mathrm{I}_{3}{ }^{-}$(Fig. 2C). All of the methods, however, exhibited $\mathrm{I}_{2}$ absorbance peaks or peak shoulders between 375 and 525 nm (Fig. 2C). Murdoch (1996) reported that the $\lambda \max$ for $I_{2}$ is $\sim 460 \mathrm{~nm}$, which matched the absorbance profile acquired using the iodometric reagents from the USDA Starch Research method (Fig. 2C). Combined interpretation from data in Table 1 and Fig. 2C show that the absorbance profiles for the methods containing $10 \% \mathrm{KI}$ and increasing concentration of $\mathrm{KIO}_{3}$, resulted in $\mathrm{I}_{2}$ peaks that shifted toward $\mathrm{I}_{3}{ }^{-}$. Yu et al. (1996) and Murdoch (1992) reported a similar trend in which excess $\mathrm{I}^{-}$increased $\mathrm{I}_{3}{ }^{-}$peak intensity and shifted the $\mathrm{I}_{2}$ peak to higher energy wavelengths. Since $\mathrm{IO}_{3}{ }^{-}$does not absorb it cannot be seen in the UV-vis spectrum, however, the $\lambda \max$ for each starch method between 350 and $550 \mathrm{~nm}$ correlated strongly with the $\mathrm{I}^{-} / \mathrm{IO}_{3}{ }^{-}$ratio for the iodometric reagents $(\mathrm{R}=0.888)$. Increased $\mathrm{I}^{-}$concentration was more critical than $\mathrm{IO}_{3}{ }^{-}$concentration, but no significant effect between either $\mathrm{I}^{-}$or $\mathrm{IO}_{3}{ }^{-}$and method sensitivity was observed (Fig. 1 and Table 1) when grouped by wavelength and equal concentrations of KI and acetic acid.

Fig. 3A shows that the average background absorbance values for the iodometric reagents decreased linearly $\left(\mathrm{R}^{2}=0.99\right)$ with increasing wavelength. Moreover, a 54\% difference in iodine background intensity occurred between the ICUMSA GS1-17 and SMRI iodometric reagents when the $\mathrm{IO}_{3}{ }^{-}$concentration was increased six-fold (Table 1 and Fig. 3B); this result was in good agreement with Chrastil (1987). Drey (1964) reported that the absorbance intensity of starch- $\mathrm{I}_{3}{ }^{-}$ 
complexes depended on both high $\mathrm{I}^{-} / \mathrm{I}_{2}$ ratio and $\leq 4.0 \mathrm{pH}$. In consequence, solution acidity based on the amount, type, and concentration of acid added was also compared to elucidate its role in the varying method sensitivities.

Acid content affected method sensitivity the most among the reagents used (Table 1 and Fig. 1), regardless of acid type, and particularly enhanced solution colour. This is largely due to hydrolysis of $\mathrm{I}_{2}$ to $\mathrm{I}^{-}$(Murdoch, 1992; Yajima et al., 1987). A further review of normalized spectra in Fig. 2C showed that increased acid concentrations among the industrial methods with equal $\mathrm{I}^{-}$and $\mathrm{IO}_{3}{ }^{-}$concentrations, e.g., ICUMSA GS1-16<SASTA<ICUMSA GS1-17, shifted the $\mathrm{I}_{2}$ peak shoulder to higher energies (Fig. 2C). The sensitivity and colour development of these methods also increased in the same order (Table 1). Chrastil (1987) explained that greater concentrations of acid enhanced the colour development of iodometric reagents but consequently their background absorbance as well. Overall, the iodometric methods that had greater acid and lower $\mathrm{KIO}_{3}$ concentrations yielded a higher absorbance for the iodometric reagent sample blanks (control). The importance of subtracting the iodometric reagents from the sample results are emphasized in Fig. 2D, in which the intensity of the $600 \mathrm{~nm}$ peak varied among the industrial starch methods. The absorbance of the iodometric reagents ultimately challenged the analytical merit of these methods and limited the starch quantification range; their impact on method accuracy and precision is demonstrated in Section 3.5.

\subsection{Accuracy and precision of the starch methods on simulated sugars}

Six simulated raw sugars, i.e., sucrose samples containing known quantities of potato and corn starch between 110 and $1000 \mathrm{mg} / \mathrm{kg}$, were used to evaluate the efficiency of the starch methods without interference from other impurities, e.g., colorants, found in factory raw sugars 
(Fig. 4 and Table 2). Accuracies for each method were assessed in several ways: 1) how do the standards affect method accuracies, 2) how well do the international industrial methods accurately measure the known starch amount, 3) which methods effectively solubilize potato and/or corn starches, 4) how did the performance of each method compare to the USDA Starch Research method, and 5) how precise are the starch methods?

\subsubsection{Effect of starch standards on method accuracy}

Fig. 4 demonstrates how each starch standard curve constructed by the USDA Starch Research method (Fig. 1B) affected the quantification of known potato and corn starch amounts in the simulated sugars. When the potato-starch standard curve was used (Fig. 4, right), the average detection accuracies for the simulated sugars containing either potato or corn starch were 81.7 and $73.1 \%$, respectively, and when a corn-starch standard curve was used (Fig. 4, left) they were 83.8 and $92.5 \%$, respectively. Regardless of the standard curve used, the USDA Starch Research method was the most accurate in detecting potato starch in simulated sugars at concentrations $<1000 \mathrm{mg} / \mathrm{kg}$ (Table 2). However, results in Table 2 also show that higher accuracies or over estimations were obtained when potato-starch simulated sugars were analyzed using a potato standard curve rather than a corn starch standard curve, and vice versa for the corn starch in simulated sugars. In both cases, the potato starch curve yielded lower accuracies (due to overestimations) than the corn starch curve (Fig. 4 and Table 2), further suggesting that raw sugars evaluated using a potato starch standard curve were incorrectly approximated. For the USDA Starch Research method, any over-estimations may be attributed to possible fragmentation of the starch chains with $\geq 6$ glucose units (Cole et al., 2016c). Baldwin (1944) reported that at least 6 glucose units are needed to bind with $\mathrm{I}_{3}{ }^{-}$to yield an absorbance. It 
must be noted, however, that the USDA method was developed for more difficult-to-solubilize starches like corn starch and sugarcane starch. However, using the corn-only standard curve, and excluding the lowest $110 \mathrm{mg} / \mathrm{kg}$ sample, the average accuracy in simulated sugars containing corn starch was $97.0 \%$ (Table 2). Both standard curves for the USDA Starch Research method were $\sim 84 \%$ accurate in quantifying the $110 \mathrm{mg} / \mathrm{kg}$ simulated sugar containing corn starch (Table 2). Many analytical methods exhibit lower accuracy for low concentrations of analytes.

\subsubsection{Accuracy of the starch methods in measuring known amounts of starch}

Table 2 also lists how well each starch method accurately measured corn or potato starch in simulated raw sugars and how they compared to the USDA Starch Research method. The ability of each industrial method to accurately measure total starch in simulated sugars was variable $(p<0.05)$ and ranged from 6 to $75 \%$ (Table 2). When the respective standard curves for each method were used, the mean accuracies of the methods decreased $(p<0.05)$ in the following order: USDA> SMRI>ICUMSA GS1-16> ICUMSA GS1-17> CSR>SASTA> Charles (Table 2). When the data was normalized to the USDA Starch Research method, the accuracies for each of the methods decreased similarly, with the exception of the interchanged order of the ICUMSA GS1-16 and ICUMSA GS1-17 methods, with significant differences between the USDA Starch Research method and theICUMSA GS1-17, SMRI, and ICUMSA GS1-16 methods (data not published). In practice, however, small variability in total starch concentrations can result in unexpected financial penalties to factories when raw sugars are delivered containing starch that is nearing the $150 \mathrm{mg} / \mathrm{kg}$ (South Africa) or $250 \mathrm{mg} / \mathrm{kg}$ (USA) limits - which are method specific - are undetected. Some refineries blend raw sugars to reduce the impurity load and its adverse effects on the refinery process, which still requires knowledge of the total concentration of starch 
in the raw sugars (Eggleston et al., 2013b; Wojtczak et al., 2014; June Naiki, ASR Group, personal communication).

\subsubsection{Efficacy of the starch methods to solubilize potato and/or corn starches}

All of the industrial methods measured potato starch more accurately $(\mathrm{p}<0.05)$ than corn starch in the simulated raw sugars (Table 2). This is most likely because these methods were developed using potato starch as a standard since corn and sugarcane starches are either difficult to solubilize and/or not commercially available. This is not encouraging because, as previously stated, the use of the incorrect starch standard can severely mislead processors and refiners regarding the amount of starch in sugarcane processing products and by-products. Accuracy varied considerably, however, with the amount of potato starch in the simulated raw sugar. The ICUMSA GS1-17 method most accurately $(\mathrm{p}<0.05)$ quantified the potato starch samples. The USDA Starch Research method was highly precise, i.e., $\leq 2.3 \%$ CV for both corn and potato starch standards, indicating that any fragmentation that occurs by the probe ultrasonicator is reproducible among analyses (Table 2). It may be possible to adjust the extent of sonication for tuberous starches to eliminate this artifact, and this is the subject of another study. Overall, the ICUMSA GS1-17 method was the most suitable in quantifying potato starch, and possibly other starches from tuberous roots such as cassava starch, with high accuracy and precision, i.e., < $13 \% \mathrm{CV}$ (Table 2).

None of the industrial methods accurately or precisely measured the amount of corn starch in the simulated raw sugars compared to the USDA Starch Research method (Table 2). The SMRI method was the most accurate among the industrial methods methods, i.e., $73.5 \%$. The other methods, however, under-estimated the known amounts of corn starch $(<67 \%)$ in the 
simulated sugars. Both the Charles and SASTA methods hardly detected any corn starch (Table 2). For four of the methods, $110 \mathrm{mg} / \mathrm{kg}$ of corn starch was too small for detection and the accuracy was low (Tables 1 and 2). For the simulated sugars containing 500 and $1000 \mathrm{mg} / \mathrm{kg}$ corn starch, only the ICUMSA GS1-16 and CSR industrial methods were able to effectively solubilize the corn starch (Table 2). This indicates that the solubilization methods using acidified calcium chloride may be more effective on sugars containing high starch but may require some readjustments to method sensitivity and lower limits of quantification. It should be noted, however, that the lower sensitivities (slopes) observed for the ICUMSA GS1-16 and CSR standard curves (Fig. 1), show that higher starch concentrations will be obtained. This may give false (inaccurate) starch concentrations, which is attributed to the $700 \mathrm{~nm}$ detection wavelength. On the other hand, the ICUMSA GS1-17 method was most effective in measuring the simulated raw sugar containing $110 \mathrm{mg} / \mathrm{kg}$ corn starch (Table 2) which agrees with Godshall et al. (2004).

As expected, a comparison of the results from the SASTA and ICUMSA GS1-17 methods indicated that corn starch became increasingly more soluble with time (Tables 1 and 2), although 2 to $5 \mathrm{~min}$ was not sufficient to completely solubilize $110 \mathrm{mg} / \mathrm{kg}$ corn starch. Cole et al. (2016c) reported that corn starch solubilization was indirectly limited by concentration and conductive boiling time. The SMRI method was relatively accurate for the simulated raw sugar containing $110 \mathrm{mg} / \mathrm{kg}$ corn starch, and in comparison to the ICUMSA GS1-17 method, it solubilized the 500 and $1000 \mathrm{mg} / \mathrm{kg}$ corn starch containing raw sugar much better (Tables 1 and 2). This is further evidence that boiling with an acidified calcium chloride solution may be a more effective approach for solubilizing sugarcane starch in raw sugars compared to boiling in only water, but can still be limited by concentration. The Charles method was ineffective because it lacked a solubilization step (Table 1). Overall, none of the industrial methods could comparably $(\mathrm{p}<0.05)$ 
solubilize corn starch as well as the USDA Starch Research method (Table 2), which will directly affect their applicability to raw sugars containing sugarcane starch.

\subsubsection{Precision of the starch methods}

Precision (or \% coefficient of variation, CV) varied among starch concentrations, starch types, and starch methods (Table 2). The USDA Starch Research method (Cole et al., 2016c), was the most precise in measuring simulated raw sugars containing either potato or corn starches, i.e., $\mathrm{CV}<1.0 \%$. Average precision decreased: Charles $>$ SASTA $>$ CSR $>$ SMR $>$ ICUMSA GS1-16> ICUMSA GS1-17>>> USDA methods (Table 2). The average precision for the Charles and SASTA methods, i.e., 26\% CV, were unacceptable by ICUMSA standards. ICUMSA typically requires that chemical analytical methods have less than $5 \%$ precision although $<10 \% \mathrm{CV}$ is sometimes accepted depending on the type of method and analyte. Only three of the industrial starch, i.e., ICUMSA GS1-16, ICUMSA GS1-17, and SMRI, methods had average $\mathrm{CV}$ values that were $<10 \%$ for simulated sugars containing either potato or corn starch.

Some variation in the methods' precisions can be attributed to the lack of method familiarity by the technician. However, a review of the raw data indicated that the varying precision was caused by the solubilization technique, LOD/LOQ, and standard curve conversion. For the majority of the methods, the worst precision occurred in the simulated sugars containing 110 $\mathrm{mg} / \mathrm{kg}$ potato or corn starch. It is well established that precision of an analytical method can vary as a function of concentration. The low $110 \mathrm{mg} / \mathrm{kg}$ starch concentration is certainly a contributing factor to the methods' lower precision values since their average starch concentrations and standard deviations were both very small and below their LOQ values. Precision for each method did improve with increasing starch concentration; unacceptable 
precision, however, was still found for the Charles and SASTA methods. Precision for the Charles method was unaffected by starch type and exhibited comparable \% CV values for corn and potato starches further implicating the lack of a solubilization method. The imprecision of the SASTA method was affected by starch type; simulated sugars containing corn starch, on average, were $3 \mathrm{x}$ worse than potato starch. This result was also attributed to the ineffective $2 \mathrm{~min}$ boiling time used for starch solubilization. Similarly, the precision of the SMRI and the ICUMSA GS1-16 methods were limited by both starch type and the low corn starch concentration. The other industrial starch methods had better precision overall and were less affected by starch type. Because of the lack of method sensitivity and detection limits (Table 1), small changes in raw absorbance data resulted in a large change in concentration, which adversely affected the precision of the industrial methods (Table 2).

\section{Conclusions}

There were clear statistical differences in the measurement of total starch by the various industrial starch methods used throughout the international sugar industry. Many of these methods are easy to perform and inexpensive but vary in their applicability to a high-throughput sampling environment and are labor intensive. Choice in starch standard adversely affects method sensitivity and accuracy. Each method covers different starch concentration ranges and varies in their limits of detection and quantification. Only the USDA Starch Research method is applicable to very-low starch containing raw sugars, albeit at a low accuracy of $83.6 \%$ and considering that $110 \mathrm{mg} / \mathrm{kg}$ starch is at the LOQ, when equated to ppm, for this method. Though the industrial methods cannot measure the same concentration range, some are capable of 
quantifying starch that is near or exceeds the starch penalty limits set by some international sugar refineries.

Wavelength detection and the composition of iodometric reagents adversely affects the accuracy of the methods, in which $600 \mathrm{~nm}$ is the most appropriately measures both starch polysaccharides complexed to tri-iodide, with the least interference from raw sugar colorants, natural juice pigments, or iodometric background colour. Current starch methods use concentrated iodometric reagents that mask low starch containing sugars. Acid content affected method sensitivity the most among the iodometric reagents.

All of the methods were more accurate in measuring potato starch in the simulated raw sugars than corn starch, and usually at total starch concentrations $>110 \mathrm{mg} / \mathrm{kg}$. None of the methods was as accurate or precise as the USDA Starch Research method because the use of a potato starch standard curve typically led to over-estimated starch values. Overall, the accuracy and precision of the current industrial methods were limited by one or more of the following variables: wavelength detection, starch concentration, solubilization method, type and concentration of iodometric reagents, and method detection and quantification limits. Considering this, in Part II of this study (Cole et al., 2017) the effects of these variables on starch quantification in factory raw sugars and the interferences of raw sugar colour were also investigated, with particular emphasis on the need for a sample colour blank and the ability to mathematically convert starch results between methods. The results presented herein will facilitate the development of a much-needed, inexpensive industrial method that effectively and accurately measures total, insoluble, and soluble starch, in sugar factory and refinery processing products and by-products, has a wide concentration range, high precision, very low limits of quantification, and uses corn starch as a standard reference. 


\section{Acknowledgements}

The authors thank Ms. Megan Shockey for her technical assistance in conducting the industrial starch methods. The authors also express gratitude to Dr. Krystal Fontenot for providing the absorbance spectrophotometer. Mention of trade names, commercial products, or methods in this article is solely for the purpose of providing specific information and does not imply recommendation or endorsement by the U.S. Department of Agriculture (USDA). USDA is an equal opportunity provider and employer.

\section{References}

Alves, F. V., Polesi, L. F., Aguiar, C. L., \& Sarmento, S. B. S. (2014). Structural and physicochemical characteristics of starch from sugar cane and sweet sorghum stalks. Carbohydrate Polymers, 111(10), 592-597. h

Baldwin, R. R., Bear, R. S., \& Rundle, R. E. (1944). The relation of starch-iodine absorption specra to the structure of starch and starch components. Journal of the American Chemical Society, 66(1), 111-115.

BeMiller, J., \& Whistler, R. (Eds.). (2009). Starch (Chemistry and Technology) (Third). San Diego: Academic Press. pp. 293-510, 567-629

Blake, J. D., Clarke, M. L., \& Littlemore, J. (1985). Some structural properties of amylopectin from sugar cane. Carbohydrate Research, 138(1), 161-167.

Charles, D. F. (1968). Quick starch method of analysis on raw sugars. Proceedings of the 1968 Technical Session on Cane Sugar Refining Research, 75-81.

Chen, J. C. P., \& Chou, C. C. (1993). Cane Sugar Handbook: A Manual for Cane Sugar Manufacturers and Their Chemists (12th ed.). John Wiley \& Sons, Inc. 
Chrastil, J. (1987). Improved colorimetric determination of amylose in starches or flours. Carbohydrate Research, 159(1), 154-158.

Cole, M., Eggleston, G., Gilbert, A., Rose, I., Andrzejewski, B., St. Cyr, E., \& Stewart, D. (2013). The presence and implication of soluble, swollen, and insoluble starch at the sugarcane factory and refinery. International Sugar Journal, 115(1380), 844-851.

Cole, M., Eggleston, G., Gilbert, A., \& Chung, Y. J. (2014). Development of a research method to measure insoluble and soluble starch in factory and refinery products. Proceedings of the Sugar Industry Technologists, LXXIII, 212-229.

Cole, M., Eggleston, G., Borges, E., Thompson, J., Rathke, T., Naiki, J., \& Triplett, A. (2016a). How the physical forms of starch affect filterability at a carbonatation refinery. Part I: Filterability of industrial sugars. International Sugar Journal, 118(1407), 204-213.

Cole, M., Eggleston, G., Rathke, T., Naiki, J., Triplett, A., \& St. Cyr, E. (2016b). How the physical forms of starch affect filterability at a carbonatation refinery. Part II: Simulated carbonatation filtration. International Sugar Journal, in review.

Cole, M., Eggleston, G., Gilbert, A., \& Chung, Y. J. (2016c). Development of an analytical method to measure insoluble and soluble starch in sugarcane and sweet sorghum products. Food Chemistry, 190(1), 50-59.

Cole, M., Eggleston, G., \& Triplett, A. (2017). Comparison of international methods for the determination of total starch in raw sugars. Food Chemistry, in review.

Davis, C. W. (1970). Colonial Sugar Refinery starch method. ICUMSA Subject 27 Referee's Report, 15th Session(London), 317-320.

Drey, R. E. A. (1964). Thresholds shown by the iodine-starch and iodideiodate-starch calibration lines. Analytical Chemistry, 36(11), 2200-2200. 
Eggleston, G., Cole, M., Gilbert, A., \& Rose, I. (2013a). A new look at starch in the sugarcane factory and refinery: the presence of soluble and insoluble starch. Proceedings of the Sugar Industry Technologists, 72(1066), 326-339

Eggleston, G., Viator, R. P., Gateuil, A., Fenger, J., White, P., Jackson, W., ... Blackwelder, N. (2013b). Effects of seasonal variations of sugarcane stalk and extraneous matter quantity and quality as they affect recoverable sugar, starch, and fiber: Part 1. International Sugar Journal, 115(1375), 477-487.

Eggleston, G. (2014). Cane Sugar Processing (Referee’s Report No. General Subject 7) (pp. 94112). Sao Paulo, Brazil: ICUMSA.

Eggleston, G., Wartelle, L., Cole, M., Montes, B., \& Pontif, K. (2016a). From juice to sugar: How insoluble and soluble starch really changes across sugarcane factories. International Sugar Journal, in review.

Eggleston, G., Montes, B., Heckemeyer, M., Cole, M., Triplett, A., Stewart, D., \& Lima, I. (2016b). Starch in Sweet Sorghum and Sugarcane: Problems, Opportunities, and Control. Advances in Sugar Crop Processing and Conversion, 1.

Eggleston, G. (2016c). Cane Sugar Processing (Referee’s Report No. General Subject 7) (pp. 128). Warsaw Poland: ICUMSA.

Figueira, J. de A., Carvalho, P. H., \& Sato, H. H. (2011). Sugarcane starch: Quantitative determination and characterization. Food Science and Technology (Campinas), 31(3).

Godshall, M. A., Clarke, M. A., \& Dooley, C. D. (1991). Starch: Process problems and analytical developments. Proceedings of the 1990 Sugar Processing Research Conference, 244264. 
Godshall, M. A., Triche, R., \& Moore, S. J. (2004). A rapid starch test for use in cane mills. Proceedings of the Sugar Processing Research Conference, 428-448.

Harrison, A. (2012). Cane Sugar Processing (Referee's Report No. General Subject 7) (pp. 2535). Bartens, Germany: ICUMSA.

ICUMSA. (2013). ICUMA Methods Book - Subject GS1 Raw Sugar. Berlin, Germany: Bartens.

Jarvis, C. E., \& Walker, J. R. L. (1993). Simultaneous, rapid, spectrophotometric determination of total starch, amylose and amylopectin. Journal of the Science of Food and Agriculture, 63(1), 53-57.

Matic, M. (1971). Starch determination in raw sugar by colorimetric methods. Proceedings of the International Society of Sugar Cane Technologists, 14, 1434-1443.

Mazumdar, N., Chikindas, M. L., \& Uhrich, K. (2010). Slow release polymer-iodine tablets for disinfection of untreated surface water. Journal of Applied Polymer Science, 117(1), 329334.

Moulik, S. P., \& Gupta, S. (1984). Stability of the amylose-iodine complex. Carbohydrate Research, 125(2), 340-342.

Murdoch, K. (1992). The amylose-iodine complex. Carbohydrate Research, 233, 161-174.

Schoonees-Muir, B. M., Ronaldson, M. A., Naidoo, G., \& Schorn, P. M. (2009). SASTA Laboratory Manual Including the Official Methods, Fifth, 1-7.

Skoog, D. A., Holler, F. J., \& Nieman, T. A. (1997). Principles of Instrumental Analysis (5th Edition). New York: Saunders College Publishing.

Thielecke, K. (2002). Cane Sugar Processing (Referee's Report No. General Subject 2) (pp. 169-189). Berlin, Germany: ICUMSA. 
Thielecke, K. (2004). Cane Sugar Processing (Referee's Report No. General Subject 2) (pp. 141-189). Berlin, Germany: ICUMSA.

Wojtczak, M., Antczak, A., \& Lisik, K. (2014). Starch content in various types of cane sugars as a criterion of quality and authenticity. International Journal of Food Properties, 17(3), $610-616$.

Woodard, H. Q. (1934). Colorimetric determination of iodine by the starch-iodine reaction. Industrial \& Engineering Chemistry Analytical Edition, 6(5), 331-333.

Yajima, H., Nishimura, T., Ishii, T., \& Handa, T. (1987). Effect of concentration of iodide on the bound species of $\mathrm{I}_{2} / \mathrm{I}_{3}{ }^{-}$in the amylose-iodine complex. Carbohydrate Research,163(1), $155-167$.

Yu, X., Houtman, C., \& Atalla, R. H. (1996). The complex of amylose and iodine. Carbohydrate Research, 292, 129-141.

Zhao, D., Glynn, N. C., Glaz, B., Comstock, J. C., \& Johnson, R. M. (2012). Development of leaf spectral models for evaluating large numbers of sugarcane genotypes. Crop Science, $52,1837-1847$. 
2 Table Captions

3 Table 1. Summary of starch industrial and research methods.

4 Table 2. Accuracy (\%) of each starch method to measure known potato or corn starch

5 concentrations in simulated raw sugars. The respective standard curve for each method (as

6 shown in Table 1) were used. Precision results $(\mathrm{CV}, \%)$ are indicated in parentheses. Note: Only

7 the USDA method had both a potato and corn standard curve because it was the only method that

8 can completely solubilize both starch forms. 
Table 1. Summary of starch industrial and research methods.

\begin{tabular}{|c|c|c|c|c|c|c|c|}
\hline & Charles & C.S.R. & $\begin{array}{l}\text { SASTA 7.8 } \\
\text { (SMRI) }\end{array}$ & $\begin{array}{l}\text { SASTA } 7.9 \\
\text { (SASTA) }\end{array}$ & $\begin{array}{c}\text { ICUMSA } \\
\text { GS1-16 }\end{array}$ & $\begin{array}{c}\text { ICUMSA } \\
\text { GS 1-17 }\end{array}$ & $\begin{array}{c}\text { USDA Starch } \\
\text { Research Method }\end{array}$ \\
\hline Standard Starch & amylopectin & potato & potato & potato & potato & potato & corn \\
\hline $\begin{array}{l}\text { Sucrose in } \\
\text { Standard }\end{array}$ & no & yes & yes & yes & yes & no & yes \\
\hline Standard Curve & $\begin{array}{c}\mathrm{Y}=0.0005 \mathrm{x}- \\
0.0024 \\
\mathrm{R}^{2}=0.9981\end{array}$ & $\begin{array}{c}\mathrm{Y}=0.0004 \mathrm{x}- \\
0.0095 \\
\mathrm{R}^{2}=0.9929\end{array}$ & $\begin{array}{c}\mathrm{Y}=0.001 \mathrm{x}-0.0202 \\
\mathrm{R}^{2}=0.9942\end{array}$ & $\begin{array}{c}\mathrm{Y}=0.0005 \mathrm{x}- \\
0.0092 \\
\mathrm{R}^{2}=0.9846\end{array}$ & $\begin{array}{c}Y=0.0003 x+0.0011 \\
R^{2}=0.9906\end{array}$ & $\begin{array}{c}Y=0.0011 x-0.025 \\
R^{2}=0.9955\end{array}$ & $\begin{array}{c}\mathrm{Y}=0.0007 \mathrm{x}-0.0003 \\
\mathrm{R}^{2}=1.000\end{array}$ \\
\hline Sample Brix & 16 & 35 & 45 & 46 & 23 & 15 & 15 \\
\hline Colour Blank & yes & yes & no & no & yes & no & yes \\
\hline $\begin{array}{c}\text { Starch } \\
\text { Precipitation }\end{array}$ & no & no & $\mathrm{EtOH}, 1 \mathrm{~h}$ & no & no & no & no \\
\hline $\begin{array}{c}\text { Method to } \\
\text { Solubilize Starch }\end{array}$ & no & $\begin{array}{c}\text { Boiling with } \\
40 \% \mathrm{CaCl}_{2}- \\
\mathrm{CH}_{3} \mathrm{COOH}, \\
\mathrm{pH} 3.0,15 \\
\text { min }\end{array}$ & $\begin{array}{c}\text { Boiling with } 40 \% \\
\mathrm{CaCl}_{2}- \\
\mathrm{CH}_{3} \mathrm{COOH}, \mathrm{pH} \\
3.0,15 \mathrm{~min}\end{array}$ & Boiling, 2 min & $\begin{array}{c}\text { Boiling with } 40 \% \\
\mathrm{CaCl}_{2}-\mathrm{CH}_{3} \mathrm{COOH} \\
15 \mathrm{pH} 3.0,15 \mathrm{~min}\end{array}$ & Boiling, $5 \mathrm{~min}$ & $\begin{array}{c}\text { Microwave, } 1 \text { min } \\
\text { and probe sonication, } \\
60 \% \text { amplitude, } 5 \\
\text { min }\end{array}$ \\
\hline $\begin{array}{l}\text { Iodometric } \\
\text { Reagent* }\end{array}$ & $\begin{array}{c}3 \% \mathrm{KI}^{-6} \\
0.6 \mathrm{MIO}_{3}\end{array}$ & $\begin{array}{c}10 \% \mathrm{KI} \\
0.01 \mathrm{MIO}_{3}\end{array}$ & $\begin{array}{c}10 \% \mathrm{KI} \\
0.01 \mathrm{M} \mathrm{KIO}_{3}\end{array}$ & $\begin{array}{c}10 \% \mathrm{KI} \\
0.0017 \mathrm{M} \mathrm{KIO}_{3}\end{array}$ & $\begin{array}{c}10 \% \mathrm{KI} \\
0.0017 \mathrm{M} \mathrm{KIO}_{3}\end{array}$ & $\begin{array}{c}10 \% \mathrm{KI} \\
0.0017 \mathrm{M} \mathrm{KIO}{ }_{3}\end{array}$ & $\begin{array}{c}8.3 \% \mathrm{KI} \\
0.001 \mathrm{M} \mathrm{KIO}_{3}\end{array}$ \\
\hline Acid* & $\begin{array}{c}0.00149 \mathrm{M} \\
\mathrm{H}_{3} \mathrm{PO}_{4}\end{array}$ & $\begin{array}{c}1 \mathrm{M} \\
\mathrm{CH}_{3} \mathrm{COOH} \\
\end{array}$ & $2 \mathrm{M} \mathrm{CH}_{3} \mathrm{COOH}$ & $1 \mathrm{M} \mathrm{CH}_{3} \mathrm{COOH}$ & $0.033 \mathrm{M} \mathrm{CH}_{3} \mathrm{COOH}$ & $2 \mathrm{M} \mathrm{CH}_{3} \mathrm{COOH}$ & $0.25 \mathrm{M} \mathrm{HCl}$ \\
\hline $\begin{array}{c}\text { Sample } \\
\text { Clarification }\end{array}$ & none & none & $\begin{array}{l}\text { Celite \& Filtered } \\
\text { (Whatman no. 91) }\end{array}$ & none & none & $\begin{array}{l}\text { Centrifuge, } \\
5 \text { min at } 3 \mathrm{k} \mathrm{rpm}\end{array}$ & Filtered, $0.45 \mu \mathrm{m}$ \\
\hline $\begin{array}{l}\text { Linear Dynamic } \\
\text { Range (mg/kg) }\end{array}$ & $0-1,000$ & $0-500$ & $0-500$ & $0-400$ & $0-250$ & $300-1,000$ & $0-3,300$ \\
\hline $\begin{array}{c}\text { LOD/ LOQ } \\
(\mathrm{mg} / \mathrm{kg})\end{array}$ & $49 / 150$ & $48 / 146$ & $53 / 160$ & $75 / 228$ & $33 / 102$ & $87 / 263$ & $8 / 24$ \\
\hline$\lambda(\mathrm{nm})$ & 560 & 700 & 600 & 600 & 700 & 600 & 600 \\
\hline Factory Product & Raw Sugars & Raw Sugar & Raw Sugar & $\begin{array}{l}\text { VHP Raw } \\
\text { Sugars }\end{array}$ & Raw Sugar & $\begin{array}{l}\text { Juice, molasses, } \\
\text { raw sugar, refined } \\
\text { sugar, syrup }\end{array}$ & $\begin{array}{l}\text { Juice, bagasse, } \\
\text { molasses, raw sugar, } \\
\text { refined sugar, syrup }\end{array}$ \\
\hline
\end{tabular}

* All reagents have been mathematically converted to the same units for comparative purposes. 
Table 2. Accuracy (\%) of each starch method to measure known potato or corn starch concentrations in simulated raw sugars. The respective standard curve for each method (as shown in Table 1) were used. Precision results (CV, \%) are indicated in parentheses ${ }^{ \pm}$. Note: Only the USDA method had both a potato and corn standard curve because it was the only method that can completely solubilize both starch forms.

\begin{tabular}{|c|c|c|c|c|c|c|c|c|}
\hline \multicolumn{9}{|c|}{ International Starch Methods (Respective Method Standard Used) } \\
\hline $\begin{array}{c}\text { Starch } \\
(\mathrm{mg} / \mathrm{kg}) \\
\text { in simulated } \\
\text { raw sugar }\end{array}$ & $\begin{array}{c}\text { Charles } \\
\text { (Potato } \\
\text { amylopectin) }\end{array}$ & $\begin{array}{c}\text { CSR } \\
\text { (Potato) }\end{array}$ & $\begin{array}{c}\text { ICUMSA } \\
\text { GS1-16 } \\
\text { (Potato) }\end{array}$ & $\begin{array}{c}\text { ICUMSA } \\
\text { GS1-17 } \\
\text { (Potato) }\end{array}$ & $\begin{array}{c}\text { SASTA } \\
\text { (Potato) }\end{array}$ & $\begin{array}{c}\text { SMRI } \\
\text { (Potato) }\end{array}$ & $\begin{array}{c}\text { USDA } \\
\text { (Potato)* }^{*}\end{array}$ & $\begin{array}{l}\text { USDA } \\
\text { (Corn) }\end{array}$ \\
\hline Potato & \multicolumn{8}{|c|}{ \% Accuracy to Known Starch Concentrations (precision, CV, \%) } \\
\hline 110 & $17.9(75.2)$ & $38.3(29.3)$ & $6.9(97.5)^{ \pm}$ & $51.9(12.9)^{* *}$ & $78.7(39.1)^{* *}$ & $94.6(7.8)$ & $87.3(0.8)^{* *}$ & $96.0(0.6) * *$ \\
\hline 500 & $8.6(79.9)$ & $63.8(7.0)$ & $86.6(8.4)$ & $65.0(8.1)$ & $64.0(30.5)$ & $76.3(9.6)$ & $75.6(0.4)^{* *}$ & $94.0(0.4)$ \\
\hline 1,000 & $4.2(14.9)$ & $67.6(7.2)$ & $97.3(3.8)$ & $71.9(4.6)$ & $71.0(16.9)$ & $58.9(2.7)$ & $82.3(2.3)$ & $61.3(2.2)$ \\
\hline Average $^{+}:$ & $10.2(27.3)^{\mathrm{e}}$ & $56.5(10.9)^{\mathrm{cd}}$ & $63.6(7.7)^{\mathrm{c}}$ & $62.9(7.9)^{\mathrm{c}}$ & $71.2(21.2)^{b}$ & $76.6(6.8)^{\mathrm{ab}}$ & $81.7(0.9)^{\mathrm{a}}$ & $83.8(0.8)^{\mathrm{a}}$ \\
\hline Corn & \multicolumn{8}{|c|}{ \% Accuracy to Known Starch Concentrations (precision, CV, \%) } \\
\hline 110 & $0.4(244.9)^{ \pm}$ & $58.0(13.6)^{ \pm}$ & $11.9(80.7)^{ \pm}$ & $85.8(4.1)$ & $3.8(217.7)^{ \pm}$ & $80.3(37.7)$ & $84.2(1.9)$ & $83.6(1.4)$ \\
\hline 500 & $4.4(16.8)$ & $77.3(6.1)$ & $110.4(3.2)$ & $56.6(7.0)$ & $18.7(63.4)$ & $72.2(2.9)$ & $65.2(1.7)^{* *}$ & $98.6(1.6)^{* *}$ \\
\hline 1,000 & $2.5(29.7)$ & $84.5(3.5)$ & $109.3(1.0)$ & $58.7(8.8)$ & $14.3(74.3)$ & $68.0(10.7)$ & $70.0(0.8)^{* *}$ & $95.4(0.8)$ \\
\hline Average $^{+}:$ & $2.4(30.0)^{\mathrm{e}}$ & $66.8(18.8)^{\text {bc }}$ & $77.2(5.9)^{b}$ & $67.0(2.3)^{\mathrm{bc}}$ & $12.3(76.6)^{\mathrm{d}}$ & $73.5(9.9)^{b}$ & $73.1(1.4)^{\mathrm{b}}$ & $92.5(1.3)^{\mathrm{a}}$ \\
\hline $\begin{array}{c}\text { Average of } \\
\text { Potato }+ \text { Corn }^{+}:\end{array}$ & $6.3(24.9)^{\mathrm{e}}$ & $61.7(14.9)^{\mathrm{bc}}$ & $70.4(6.7)^{\mathrm{bc}}$ & $64.9(4.2)^{\mathrm{bc}}$ & $41.8(25.8)^{\mathrm{d}}$ & $75.0(7.8)^{\mathrm{b}}$ & $77.4(1.1)^{\mathrm{b}}$ & $88.2(0.9)^{\mathrm{a}}$ \\
\hline
\end{tabular}

†Percent accuracy (\%) was calculated as follows: [1 - (|Factory Method Starch Result - USDA Starch Research Method Starch Result//USDA Starch Research Method Starch Result)] x 100\%. *The USDA starch method does not incorporate a potato starch standard curve. A potato curve was only generated for investigation purposes only. $* *$ Results yielded values greater than $100 \%$ which, if included, caused false, higher ( $<<0.05)$ average accuracies. ${ }^{+}$Average results followed by the same lower case letter among columns are not significantly different at the 5\% probability level. ${ }^{ \pm}$Precision data was calculated after adjusting all negative starch values to zero. 


\section{Fig. Captions}

Fig. 1. A) Overlay of the standard curves obtained with each of the industrial and research starch methods. B) Comparison of standard curves constructed with corn starch or potato starch using the USDA Starch Research method.

Fig. 2. A) Colour theory wheel illustrating the relationship between amylose (blue), amylopectin (red-violet), and amylose-amylopectin mixtures (purple) solution colour and the detecting wavelengths of the starch method. UV spectra of the iodometric reagents with amylose (B) and without amylose $(\mathrm{C})$ using the various industrial starch methods. The spectra in figure $\mathrm{C}$ were normalized to the $\mathrm{I}_{2}$ peak for comparison. D) UV spectra of amylose- $\mathrm{I}_{3}$ complexes after subtracting the iodometric reagents.

Fig. 3. Average background absorbance values for the iodometric reagents used, by wavelength (A) and method (B).

Fig. 4. Mean accuracies of the USDA method in detecting potato or corn starch in simulated raw sugars using either a corn (red) or potato (blue) starch standard curve. Mean \% accuracies are denoted on the top of each column. 
A)

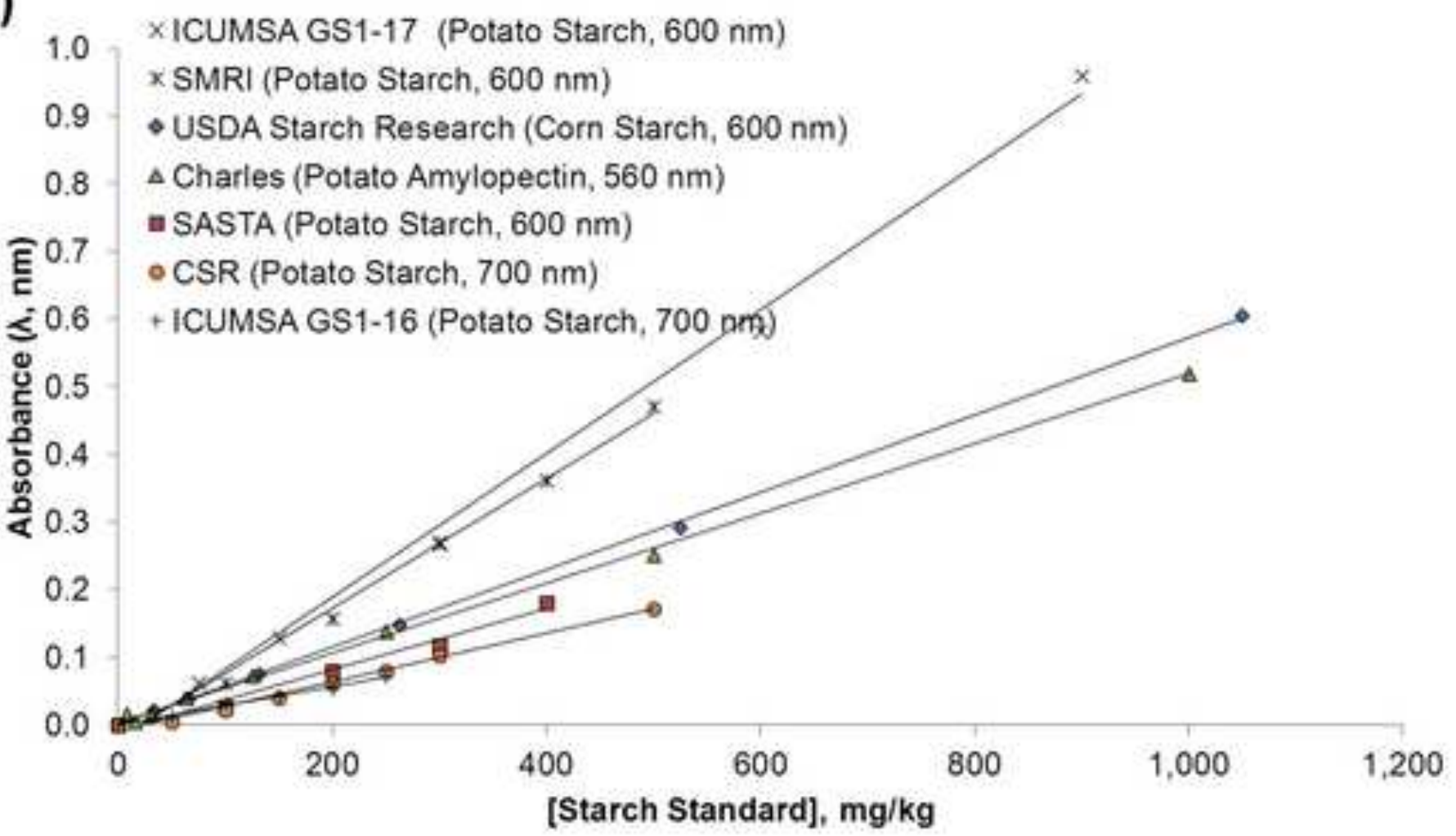

B)

- - Corn Starch Curve $\quad \approx$ Potato Starch Curve

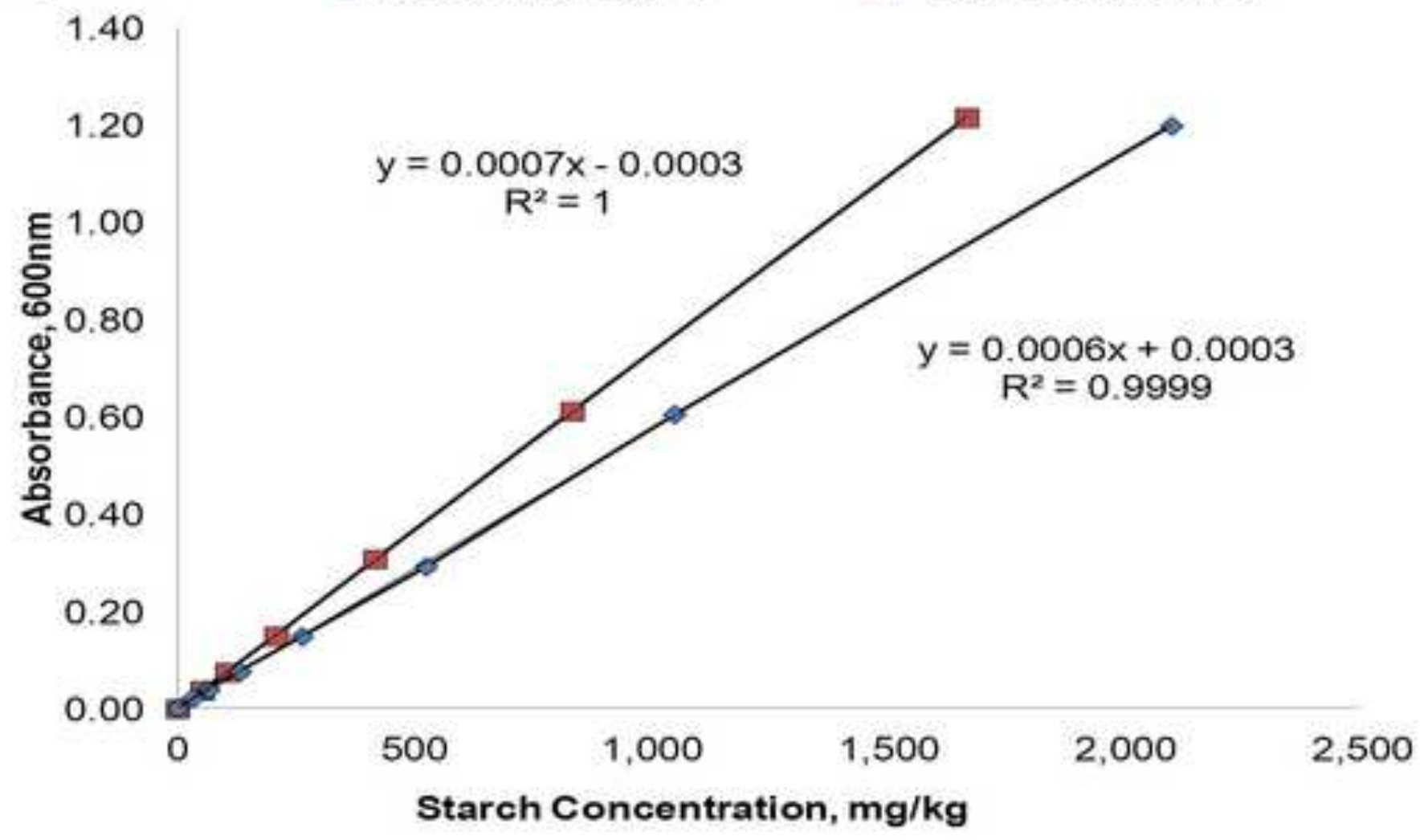



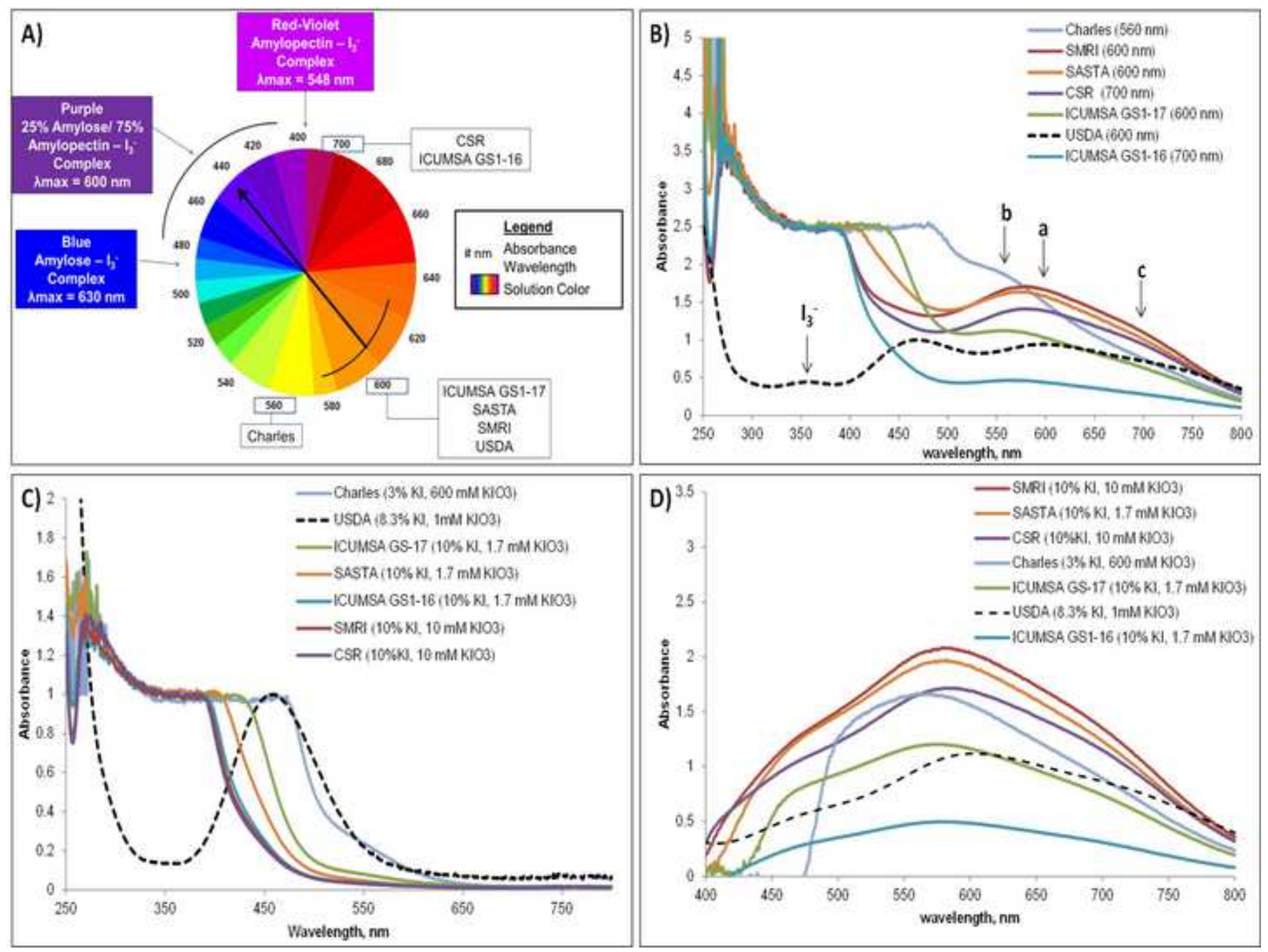
A)

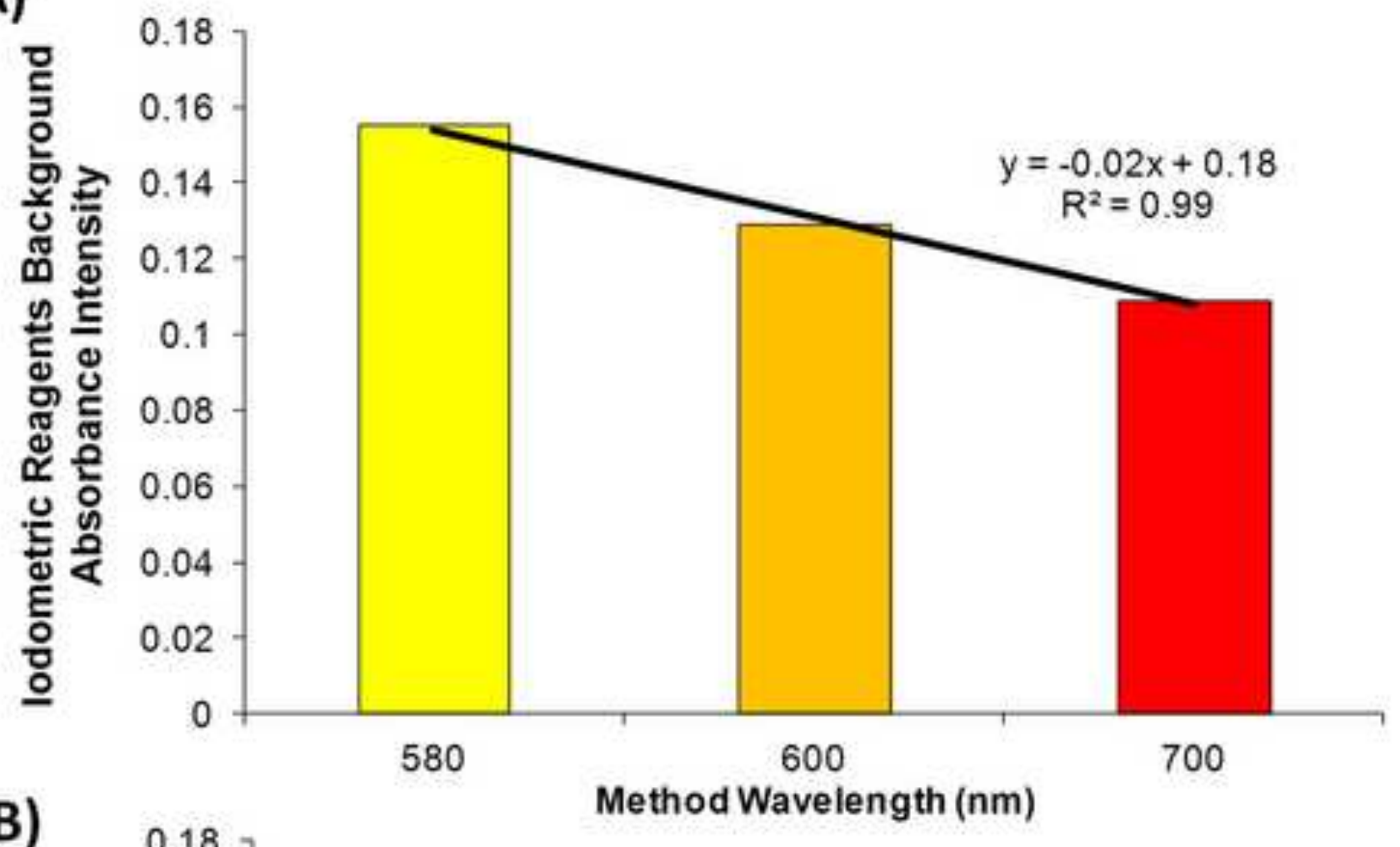

B)

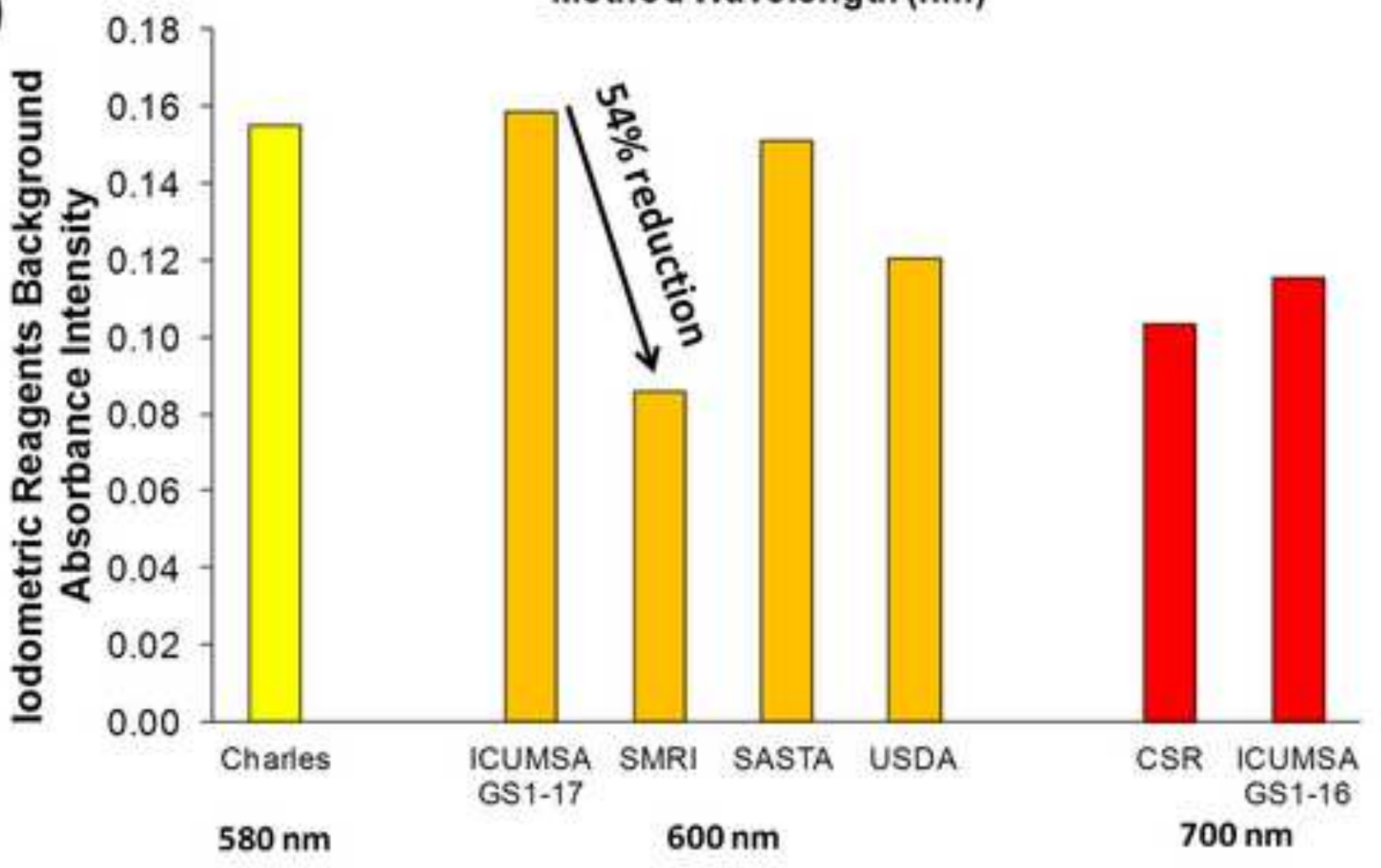


- (\%) Corn Curve (\%) Potato Curve

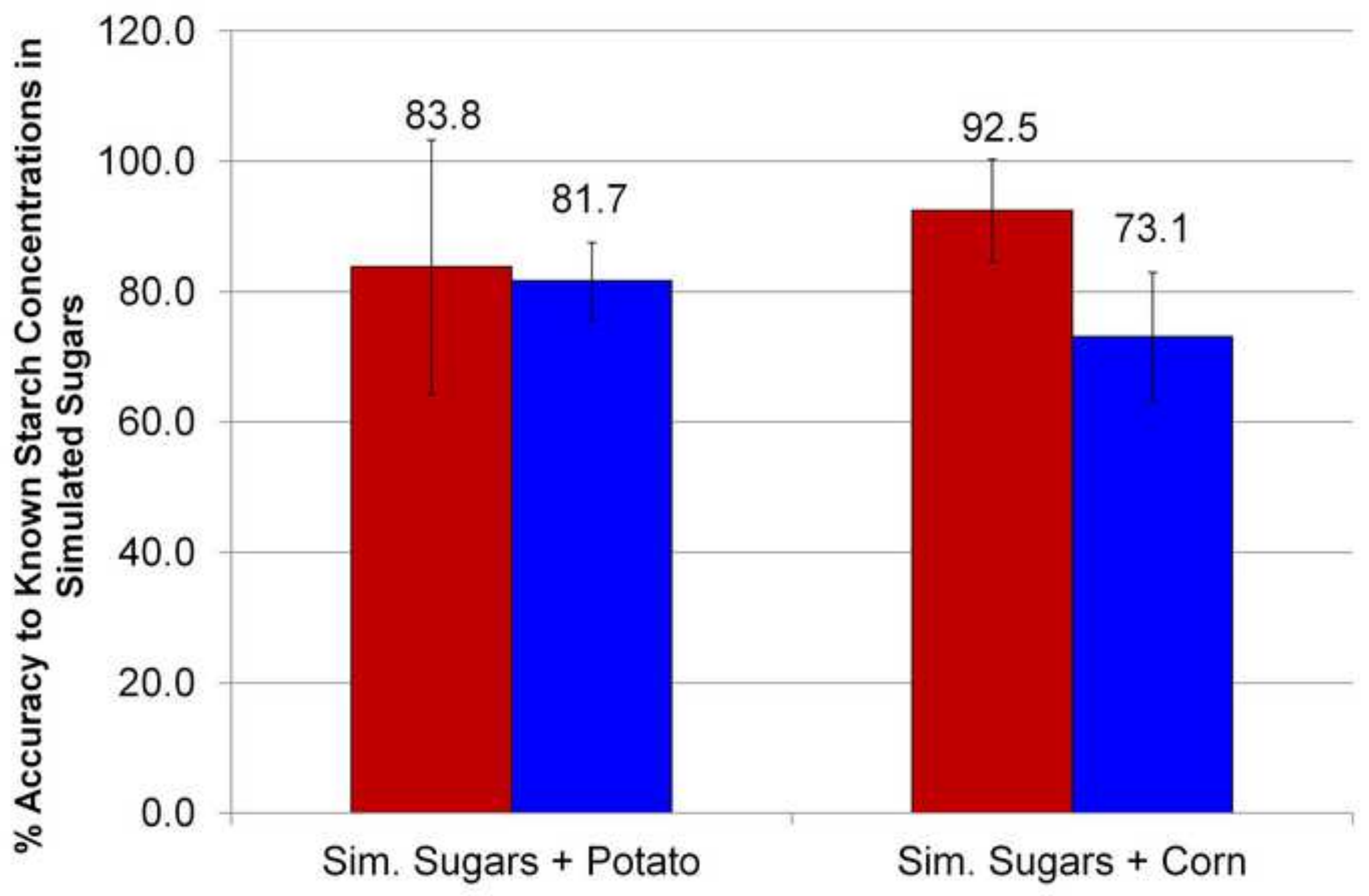

